\title{
Instruction Design and Strategy of Concept Mapping
}

\author{
Shun-Ho Wang \\ School of Education Science \\ Zhaoqing University \\ Zhaoqing, China
}

\begin{abstract}
The focus of this study is to apply the concept mapping method to innovate curriculum design. The study purpose is to explore how to use the teaching method of concept mapping to help learners build knowledge scaffolding, so that learners can organize scattered knowledge and construct meaningful knowledge through concept mapping. In other words, it helps learners to present abstract concepts in a concrete way, and to clarify the relationship between concepts and facts, and to connect new information and prior knowledge in order to make meaningful learning. Of course, this study also analyzes the advantages and disadvantages of concept mapping and its limitations. Although it has some disadvantages, such as time-consuming, more subjective, as well as providing no explanation for the concept itself, and so on, the teaching method of concept mapping has more advantages than disadvantages. It visualizes important facts, concepts and relationships. It not only contributes to the construction and memory of knowledge, the communication and negotiation of meaning, the evaluation and improvement of learning results, but also contributes to the organization of information and the innovation of ideas. It is still regarded as a powerful teaching tool.
\end{abstract}

Keywords-concept mapping; knowledge construction; scaffolding; meaningful learning

\section{INTRODUCTION}

According to relevant educational research, although the traditional static narrative method is convenient for teaching and learning knowledge, however, it is easy to cause the lack of learners' sense of participation, learning attitude, the disconnection between theory and practice, etc. Therefore, it is inevitable that the teaching design reform should be carried out in response to these deficiencies, and the instruction design of concept mapping will replace the static and monotonous traditional teaching to further observe and reflect on the teaching process.

The concept mapping is not only helps students to focus on important concepts, but also helps students to grasp the correlation between these concepts. Many studies have also confirmed that concept mapping can indeed help students engage in meaningful learning.

\section{THE MEANING OF CONCEPT MAPPING}

\section{A. Concept Implication and Learning of Knowledge Structure}

In the process of cognitive structure and cognitive development, "concept" is a symbolic construction. When "concept" was applied to cognitive learning, the learning of knowledge structure not only focuses on the learning of "points" (i.e. single concept), but also extends to the learning of "surfaces" (similar to network context), which is also a meaningful structured learning method [1].

\section{B. The Basic Concept of Concept Mapping}

Concept mapping was proposed by Novak and Gowin. It is composed of propositions, each of which includes two concept nodes and the connection between concepts. It is the construction process of concept mapping. The learner abstracts the concepts from the teaching, takes a "core concept" as the theme, and organizes all related concepts around this core concept to become a semantic network diagram representing the overall knowledge structure.

\section{The Instruction Design PhILOSOPHY OF CONCEPT MAPPING}

The instruction design philosophy of concept mapping includes teaching objectives, steps and strategies, which is also the guiding principle of teaching design.

\section{A. Teaching Objectives}

Concept mapping should be effective; it must focus on the acquisition of goals at three levels:

- It must improve students' academic performance.

- It must guide students to use concept mapping.

- It must develop students' ability to understand the composition of concepts about themselves.

\section{B. Scaffolding}

1) The presentation of examples: Teachers could provide at least one typical example to be applied.

2) The demonstration: Teachers could demonstrate and illustrate the drawing process, so that students can understand the drawing steps of the example. 
teaching, and the feedback and evaluation stage after teaching.

\section{A. Preparation Before Teaching}

1) Teaching objectives: The goal of teaching is to define each learning unit by the representation function of concept mapping, and it converts the learning content into appropriate concept mapping gradually, so as to help students learn knowledge effectively in this field.

2) The subject of the textbook: Teachers must organize the course according to the teaching content. They would confirm the theme of each unit, list all the key words, and then select the key words that students must know to form the concept.

3) Analysis of students' entry behavior: The entry behavior is the teacher's assessment of the students' learning ability from the old experience, which plays a guiding role in teaching process. If the student's entry behavior is not enough to link the new learning, the teacher must strengthen it, so as to improve the effectiveness of teaching.

4) Teaching strategies: Teachers must understand the drawing process of concept mapping, so that the concepts of the theme can be properly presented in the concept mapping, and to make the students feel easy and interesting.

5) The type of concept mapping to use: Common concept mapping can be divided into three categories:

- Concept maps to link related concepts;

- Concept maps to present causal relationships;

- Concept maps to evaluate ideas.

They contain five main types: fishbone diagrams, spider maps, chain maps, hierarchy maps and mind mapping. Each of these five types has its own application, and each of them can play a different role in learning. Teachers can consider the objectives of the course and choose the appropriate type of concept mapping.

\section{B. The Interactive Stage in Teaching}

1) The beginning stage of teaching: At this stage, teachers must complete four tasks as follows.

a) Description of course objectives and unit activities: Teachers state the deep meaning of the objectives of the course and the unit activities of concept mapping, the publishing methods of the works, the evaluation methods and standards. At this stage, teachers must be able to arouse students' attention and motivation.

b) The unit activity of "paint me": In order to get to know the students better and get them interested in painting, the researchers sent out a "self-introduction form" and asked the students to draw a self-portrait. In this way, students begin to connect with painting.

c) Groups of cooperative learning: Teachers randomly match the whole class to form several groups, and guide the team naming and role assignment. Then, based on the concept of the unit course, the teacher arranged the
The practical application of concept mapping in teaching process, there are three stages of practical content, including the preparation before teaching, the interactive stage in 
learners' understanding and memory and help them to encode the learning content. It also enables the teacher to examine the teaching effect in time to correct or supplement the teaching. Ten minutes before the end of the class, each student recalls the concept mapping that completed by each group and redraws it again. Then the other members of the group review and supplement it.

3) Feedback and sharing from each group: Through cooperative discussion and information sharing among each group. Students overcome learning difficulties and improve motivation and effectiveness.

\section{REFLECTION}

Concept mapping is a visual organization tool; it accords with the cognitive representation theory of cognitive psychology, the knowledge construction of constructivism, and meaningful learning of educational psychology. Therefore, it is a teaching and learning strategy widely applied in scientific education and psychological education [2].

However, it is not a perfect teaching method, which naturally has its limitations and deficiencies. Its advantages and disadvantages and limitations are as follows:

\section{A. Advantages of Concept Mapping}

1) Concept mapping organizes concepts, which promote meaningful learning for learners: The concept mapping presents the complex knowledge structure with simple graphics and the connections between knowledge points, which can help learners connect new knowledge with existing concepts and promote students' meaningful learning.

2) Concept mapping could support the overall learning style and enhance the understanding of concepts: Concept mapping can be used to distinguish conceptual hierarchies, relationships, and other meaningful conceptual patterns through causal connections to improve the understanding of concepts.

3) Concept mapping could help students with selfreflection: When learners draw the knowledge they have learned into a concept mapping, they can grasp the overall structure of knowledge, find out the gaps in their own knowledge and make up for the gaps in time. In addition to improving the reflective ability of learners, they also cultivate their information literacy in the process of collecting materials.

4) Concept mapping could promote dialogue between students: Concept mapping organizes information around the main points. When learners are learning a certain content, they can draw a concept mapping of the theme through the group, and carry out communication and discussion among group members and groups, so as to cultivate their sense of cooperation and enhance their interpersonal communication skills.

5) Concept mapping could promote the dialogue between students and the text: Students are guided to 


\section{REFERENCES}

"reproduce" the texts so as to reconstruct a set of knowledge about the teaching topics.

\section{B. Disadvantages and Limitations of Concept Mapping}

1) The presentation of concepts tends to be simple: Concept mapping tends to become a simple arrangement of concepts, because the metacognition of concept mapping is ignored. In the process of composition, learners are unable to represent their inner thinking mode, so they cannot achieve the expected learning effect.

2) The evaluation results tend to be subjective rather than objective: The evaluation of concept mapping tends to be subjective and lacks objective criteria, because it overemphasizes the accuracy of concept mapping. It must use multiple assessment methods to be more perfect and objective, in order to really touch the real focus of teaching.

3) It is time-consuming to draw with paper and pen: Students usually spend a lot of time and energy to revise the concept mapping with pen and paper, they cannot concentrate on the cognition of the concept. In the same way, teachers often have to spend a lot of effort to evaluate the concept maps of all students, which often directly affect the results of the concept mapping. With computer assistance, the revision of the concept map will be easy for students to build and draw. Furthermore, the advantages of computer assisted assessment, with its automatic recording and scoring functions, have been generally recognized.

4) The concept mapping provides no explanation for the concept itself: Concept mapping is much like a jigsaw puzzle, it has the advantage of connecting concepts so that learners can know where they are in the learning process, but the interpretation of the concept itself is less provided. Therefore, concept mapping is doubted to provide complete learning connotation.

\section{CONCLUSION}

In short, concept mapping can present knowledge in a full picture, rather than as a single statement. It makes students realize that understanding is more important than memorizing, and share each person's different knowledge and ideas. However, its disadvantages are time-consuming, more subjective, and it provides no explanation for the concept itself.

The teaching method of concept mapping has more advantages than disadvantages. It visualizes important facts, concepts and relationships. It not only contributes to the construction and memory of knowledge, the communication and negotiation of meaning, the evaluation and improvement of learning results, but also contributes to the reorganization of information and the innovation of ideas. It is certainly regarded as a powerful teaching tool. That is to say, it is still worth applying in practice, especially in traditional schools where teaching methods rarely change, it will be more helpful to use this teaching strategy.
[1] J. D. Novak, \& D. B. Gowin, Learning how to learn. London: Cambridge University Press, 1984.

[2] J. D. Novak, Concept maps and Vee diagrams: Two metacognitive tools for science and mathematics education. Instructional Science, Vol. 19, 1990, pp.29-52.

[3] D. Hyerle, Thinking maps: Seeing is understanding. Educational Leadership, Vol. 53, No. 4, 1996, pp.85-89.

[4] S. B. David, High school biology: A group approach to concept mapping. The American Biology Teacher, Vol. 65, No. 3, 2003, pp.192-197. 